\title{
Health Monitoring of Civil Infrastructures Designed with Pre-stressing Steel
}

\author{
Md. Shahidul Islam ${ }^{(\bowtie)}$ \\ HQ Technical Services, Dywidag-Systems International, Bolingbrook, IL, USA \\ shahid.islam@dsiamerica.com
}

\begin{abstract}
Our infrastructure is expanding and the existing infrastructure is aging. Some structures are expensive to maintain and some occasionally fail. Health monitoring of structures has become a hot topic discussed among owners, engineers, contractors and the general public at large. Pre-stressing steel is an important part of the structure where it is installed. Unfortunately there are limited testing methods available to assess the force in the pre-stressing steel. High cost, complicated equipment and limitation of space often prevent these methods from being implemented. DYNA Force sensors have been developed to measure the force in the pre-stressing steel during construction and at any time during the lifetime of the structure. In addition to the long-term monitoring benefit of using the sensor, it may also be used to check the load during stressing to address the safety of the structure. It will eliminate the use of large equipment during lift-off operation. These sensors are manufactured based on the magnetoelastic properties of ferrous material. A readout unit is designed to magnetically energize the steel through the sensor and measure the response of the steel to a direct force reading. The force reading can be collected manually, automatically and also remotely. They can be used for bare, epoxy-coated, galvanized and greased-sheathed steel in bonded, un-bonded, grouted or un-grouted length of the tendon/anchor. It has received attention in terms of accuracy, its performance, ease in installation, durability, and cost effectiveness. It has been used in over seventy projects in various parts of the world. Its application in bridges, buildings, tunnels, retaining walls and dam structures is presented.
\end{abstract}

\section{Introduction}

Tie-backs, retaining walls, dams and other geotechnical structures use pre-stressing steel ground anchors and many of them need repair using ground anchors. Bridges are an essential part of a highway network. Post-tensioning and cable stays are essential elements of a bridge where they are installed. Pre-stressing steel is used in tunnels, concrete wind towers and in many building structures. There is a large demand for implementing health monitoring of structures. On many occasions during construction and service life of the structure, it is required to know the force in pre-stressing steel. Lift-off is done for cable stays at various stages of its construction to know the force in the stays. There is a trend in ground anchor specifications where the engineer calls for re-stressable anchor. The engineer needs to know the force in the anchor to decide if re-stressing is required. If not instrumented there is no way to check how these anchors 
are performing and also the condition after any major event takes place. Among available instruments strain gauges, load cells or fiber optics are pre-installed. Mounting of strain gauges and fiber optics are challenging. Many of them get damaged during coiling and uncoiling of anchors. Load cells when used require larger block-out to stress and larger cap to protect the end of anchor. Most do not provide reliable data after few years in service.

The elasto-magnetic (EM) technology is a novel approach to monitor forces in steel elements (Wang et al. 1998). The EM method is a valuable tool in Civil Engineering for estimation of the real stress in the prestressing tendons (Fabo et al. 2004). Magnetic properties of the steel depend on the actual stress and temperature. The relationship between the increased permeability of the steel, stress and temperature can be used for the estimation of the real average stress in the measured cross-section of the steel.

DYNA Force sensor is built based on EM technology (See Fig. 1). It is composed of a primary coil and a secondary coil (sensing coil). By passing current through the primary coil, ferromagnetic material is magnetized. The sensing coil picks up induced electromotive force that is proportional to change rate of applied magnetic flux (Faraday's law) and relative permeability. As permeability of core changes, output voltage changes. The output voltage is calibrated to measure the force. A readout unit is designed to magnetically energize the steel through the sensor and measure the response of the steel to the process. The readout unit then converts the response into a direct force reading. The sensor has an embedded thermistor which provides temperature reading and is used for temperature compensation. Due to the diversity of the magnetic property of steel, calibration is done for each type of steel allowing the sensors to perform at their highest accuracy.

$$
\varepsilon=-\frac{d}{d t}\left(\phi_{B}\right)
$$

Where, $\varepsilon=$ electromotive force

$$
\phi_{B}=\text { magnetic flux }
$$



Fig. 1. Indicative working chart of elasto-magnetic sensor 
Sensors are cylindrical in shape and are installed over steel elements prior to stressing. The sensor is robust, requires no maintenance, has no moving parts and is not subject to any load. It is expected to have a similar service life to that of the surrounding structure. They can be used for bare, epoxy-coated, galvanized and greased-sheathed steel in bonded, un-bonded, grouted or un-grouted length of the tendon (See Fig. 2). In addition to the long-term monitoring benefit of using the sensor, it may also be used to check the load during stressing to address the safety of the structure and people around it. It will eliminate the use of large equipment during lift-off operation. The accuracy of the force measurement using sensors is equal or better than the load cells.

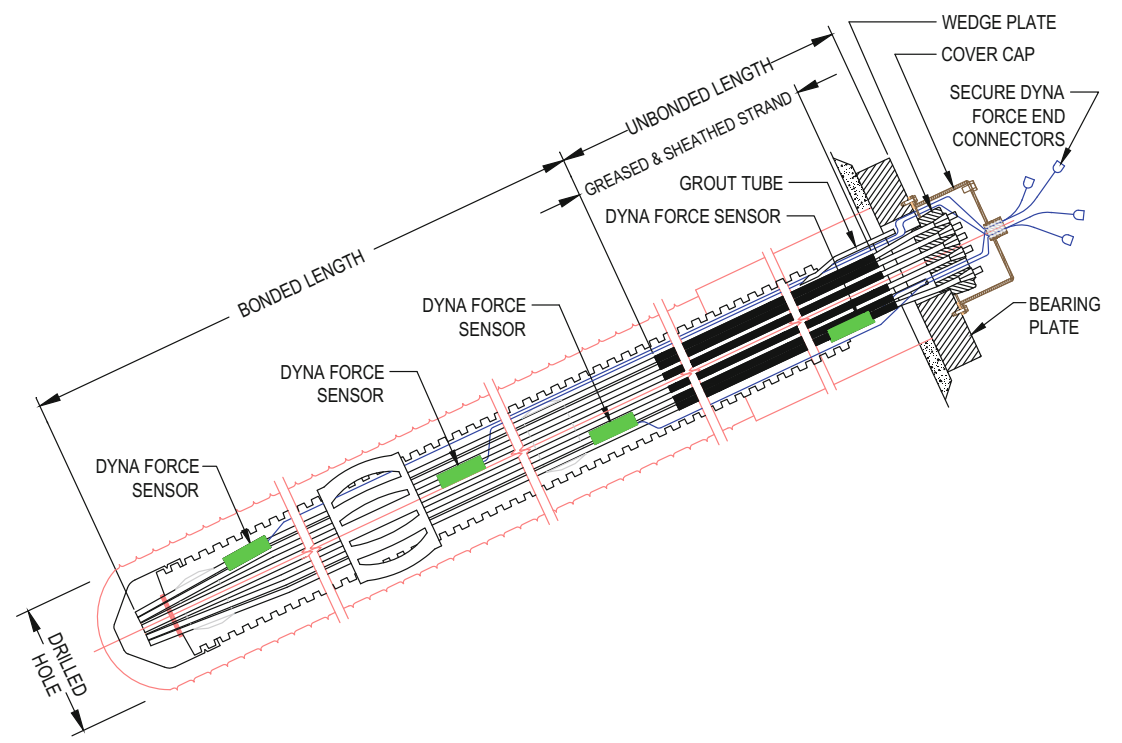

Fig. 2. Sensors in bonded and unbonded length

\section{Sensor Development}

Sensors were developed for strands and high strength bars. Intense testing program was undertaken to improve the accuracy and reliability of sensor readings. Figure 3 shows the sensor calibration and testing setup. Sensor is placed over the strand/bar in the loading frame. Load cell is used at one end and the jack is used on the other end. Load is applied to the strand/bar using the jack and the force in the strand/bar is measured by sensor at various steps of loadings are recorded and compared with the load cell readings. Figure 4 shows the comparison of the strand sensor with the load cell readings at various stages of loadings. As seen in Fig. 4, the sensor readings were very close to the load cell readings during each step of loadings and show consistent readings during loading and unloading cycles as well, which guarantee the repeatability of the actual readings. 




Fig. 3. Sensors calibration and test setup

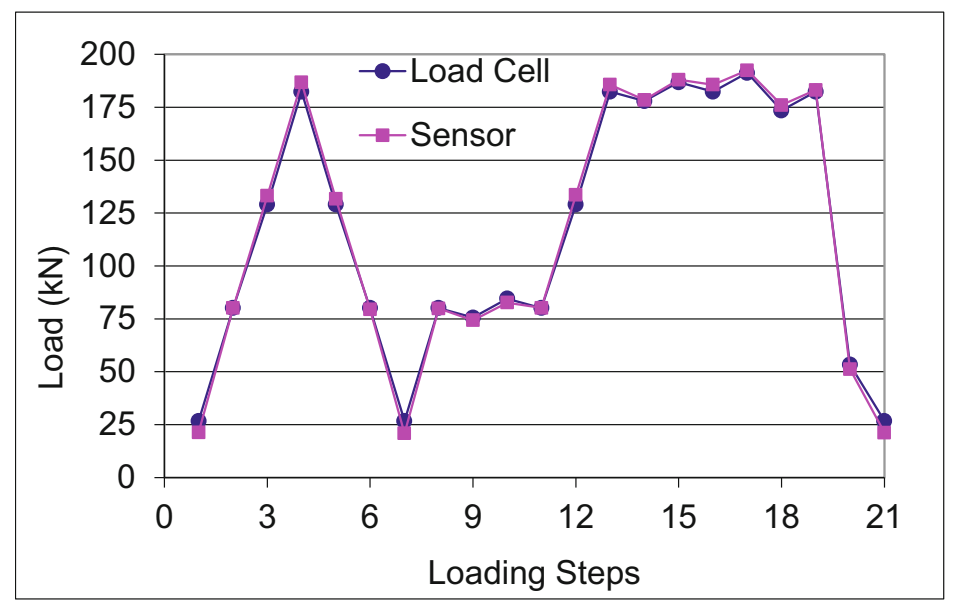

Fig. 4. Comparison of strand sensor readings

\section{Sensor System}

The Sensor System consists of mainly sensor and readout unit (See Fig. 5) and dimensions of sensors are shown in Table 1. Additional cable connections, multiplexers, modem \& controller are required for continuous and remote readings. In the Manual option, each sensor is individually connected to the readout unit and the force in the strand or bar is measured in a few seconds. 
(a)

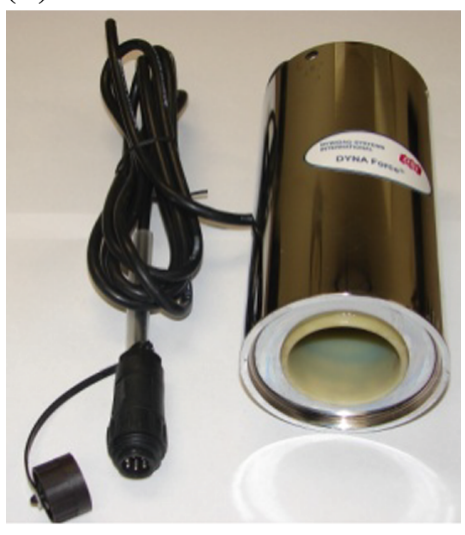

(b)

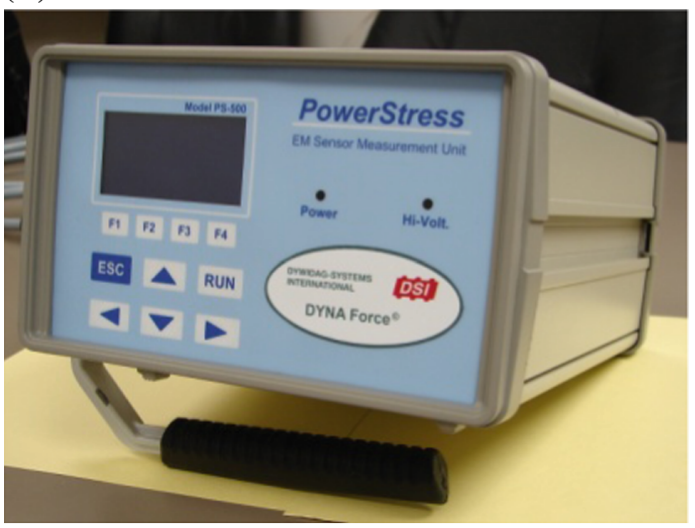

(c)

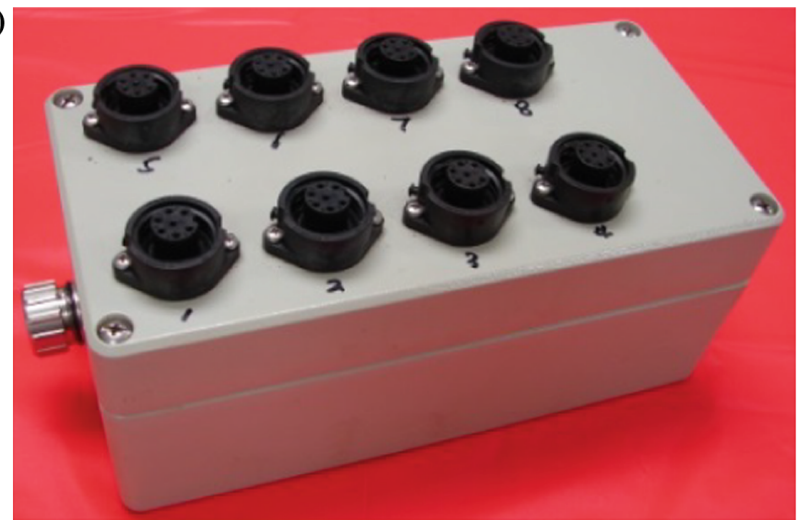

Fig. 5. (a) Sensor, (b) Readout unit, (c) Multiplexer

In the Automated option, all sensors are connected to the readout unit using extension cables, multiplexers and main cables. The readout unit is programmed to record the temperature and force readings of all sensors at a pre-set time interval. It can record up to a maximum of 2,400 sets of data. The recorded data may be downloaded to a laptop computer using a RS232 port attached to the Unit. The data is in Txt or ASCII format and can be imported to other programs and analyzed.

In the Remote option, all sensors are connected to the readout unit using extension cables, multiplexers and main cables. A modem and a controller are also attached to the readout unit. A cellular SIM card with a data plan or Ethernet terminal server is installed to communicate from a remote computer with a static IP address. Software is provided to collect data from the readout unit through a RS232 port. It can either take readings from a remote computer as needed or can get data stored at specified intervals in the readout unit positioned at the point of use. The output from the readout unit may be incorporated into other data acquisition systems as well. Data is in Txt or ASCII format and can be imported to other programs and analyzed. 
Table 1. Sensor dimensions

\begin{tabular}{l|l|l|r|l}
\hline Strand size $[\mathrm{mm}]$ & Strand grade $[\mathrm{MPa}]$ & \multicolumn{3}{|l}{$\begin{array}{l}\text { Sensor dimensions } \\
(\mathrm{mm})\end{array}$} \\
\cline { 3 - 5 } & & I.D. & O.D. & Length \\
\hline $12.7-15.7$ & 1860 & 20 & 36 & 132 \\
\hline Bar size [mm] & Bar grade [MPa] & \multicolumn{3}{|l}{$\begin{array}{l}\text { Sensor dimensions } \\
\text { (mm) }\end{array}$} \\
\cline { 3 - 5 } & & $\begin{array}{l}\text { I.D. } \\
\text { nyyyy}\end{array}$ & O.D. & Length \\
$16-35$ & $515-670$ & 43 & 80 & 180 \\
\hline 43 & $515-670$ & 53 & 99 & 200 \\
\hline $57 / 63$ & $515-670$ & 73 & 145 & 310 \\
\hline 75 & $515-670$ & 85 & 155 & 330 \\
\hline $26-36$ & 1050 & 43 & 80 & 180 \\
\hline $40 / 46$ & 1050 & 53 & 99 & 200 \\
\hline 66 & 1050 & 73 & 145 & 310 \\
\hline 75 & 1050 & 85 & 155 & 330 \\
\hline
\end{tabular}

Sensor over the tendon X-section is custom made and dimensions will be provided upon request.

\section{Sensor Applications}

Sensors have been successfully used in cable stay, post-tensioning tendons in bridge and building structures, ground \& tie-back anchors, retaining walls, dams, air traffic control tower, wind energy tower and repair of various post-tensioned structures (Islam 2008, 2014; Islam and Purinton 2015). Some of the sensor applications in bridges, building and geotechnical structures are presented below.

Two-hundred forty sensors were used in Penobscot Narrows Bridge, Maine, USA. The cable stays were of epoxy coated strands varying from 41 to 72 (15.2 $\mathrm{mm}$ dia strands). Sensors were mounted to the anchor using a holder (See Fig. 6). Each cable had six sensors (three at each anchor location) allowing the cable forces at each stage of construction to be monitored using these sensors. Periodic lift-off operations were additionally made on the strands with sensors, and a good correlation between target and sensor forces was observed. The bridge is now open to traffic and the forces in any cable can be monitored anytime using the sensors without any disruption to the traffic. Sensors readings for half of main span stays after 7 years in service are compared with maximum and minimum design force as shown in Fig. 7. All cable forces were found within design maximum and minimum forces.

Sensors were utilized to monitor the force in 1-3/4" (46 mm) $150 \mathrm{ksi}$ (1035 MPa) post-tension bars in the vertical wall of Wind Technology Testing Center in Boston, MA, USA. All lead wires with end connectors were routed to the outside of the wall as in Fig. 8. The forces were monitored during construction and then again two months 

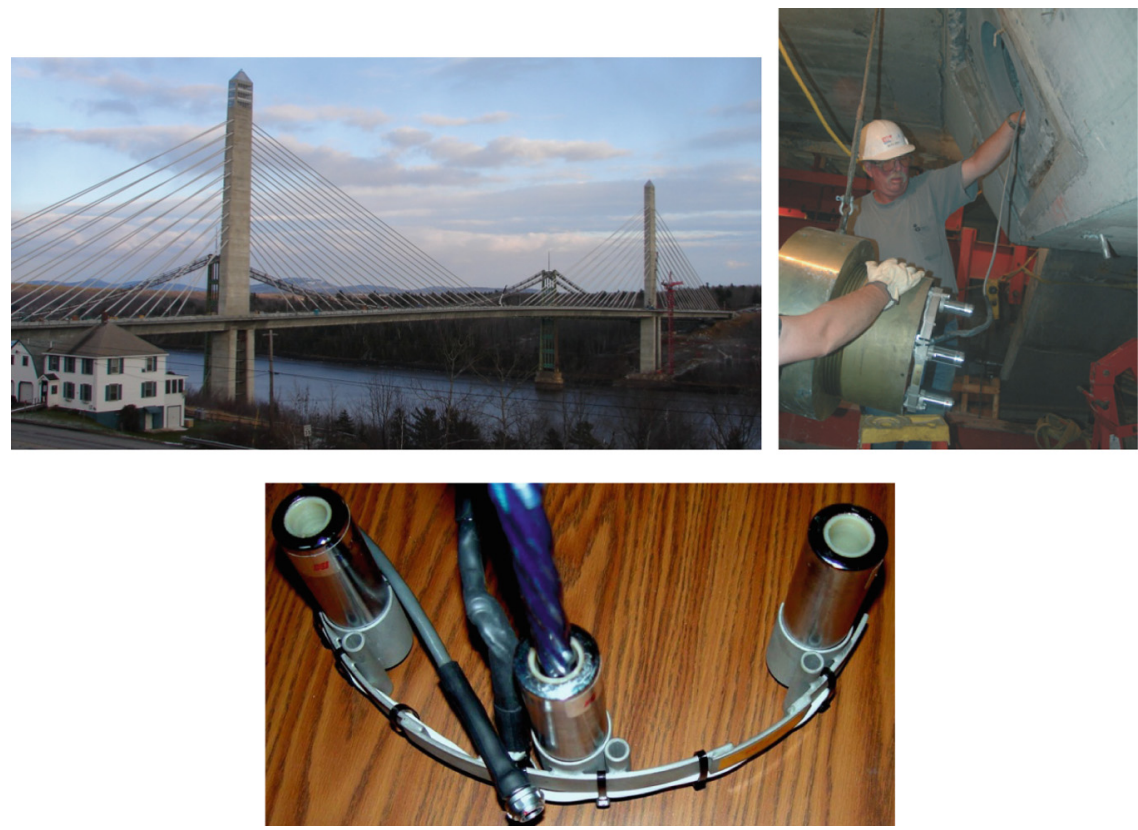

Fig. 6. Sensors for Penobscot Narrows Bridge, Maine, USA

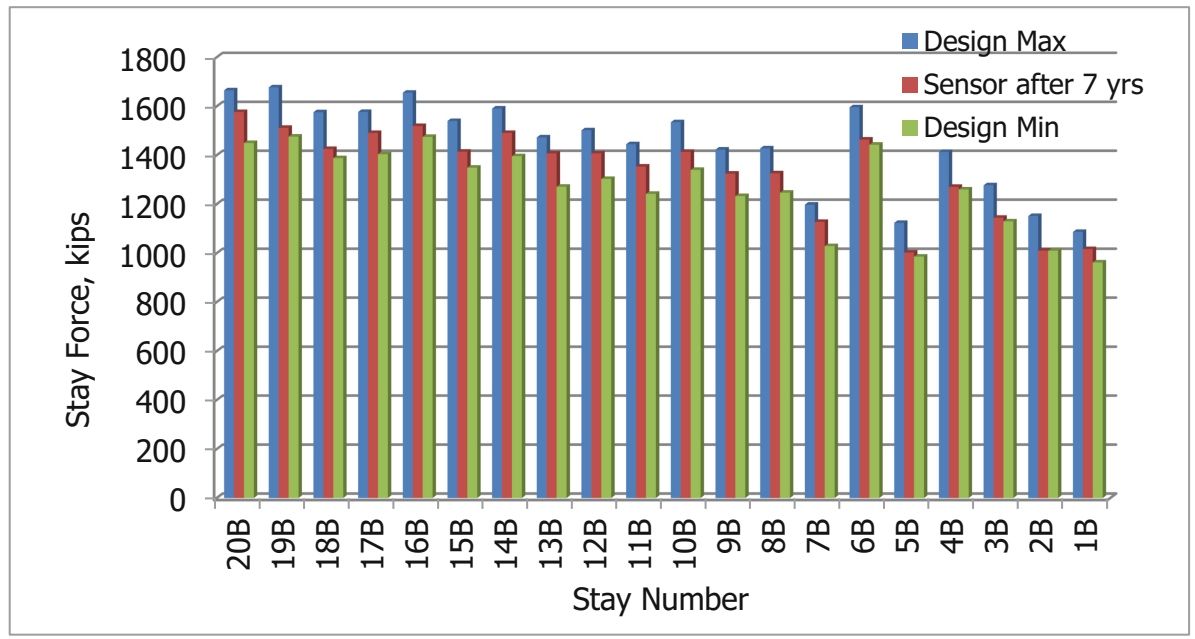

Fig. 7. Comparison of sensor data for Penobscot Narrows Bridge, Maine, USA 

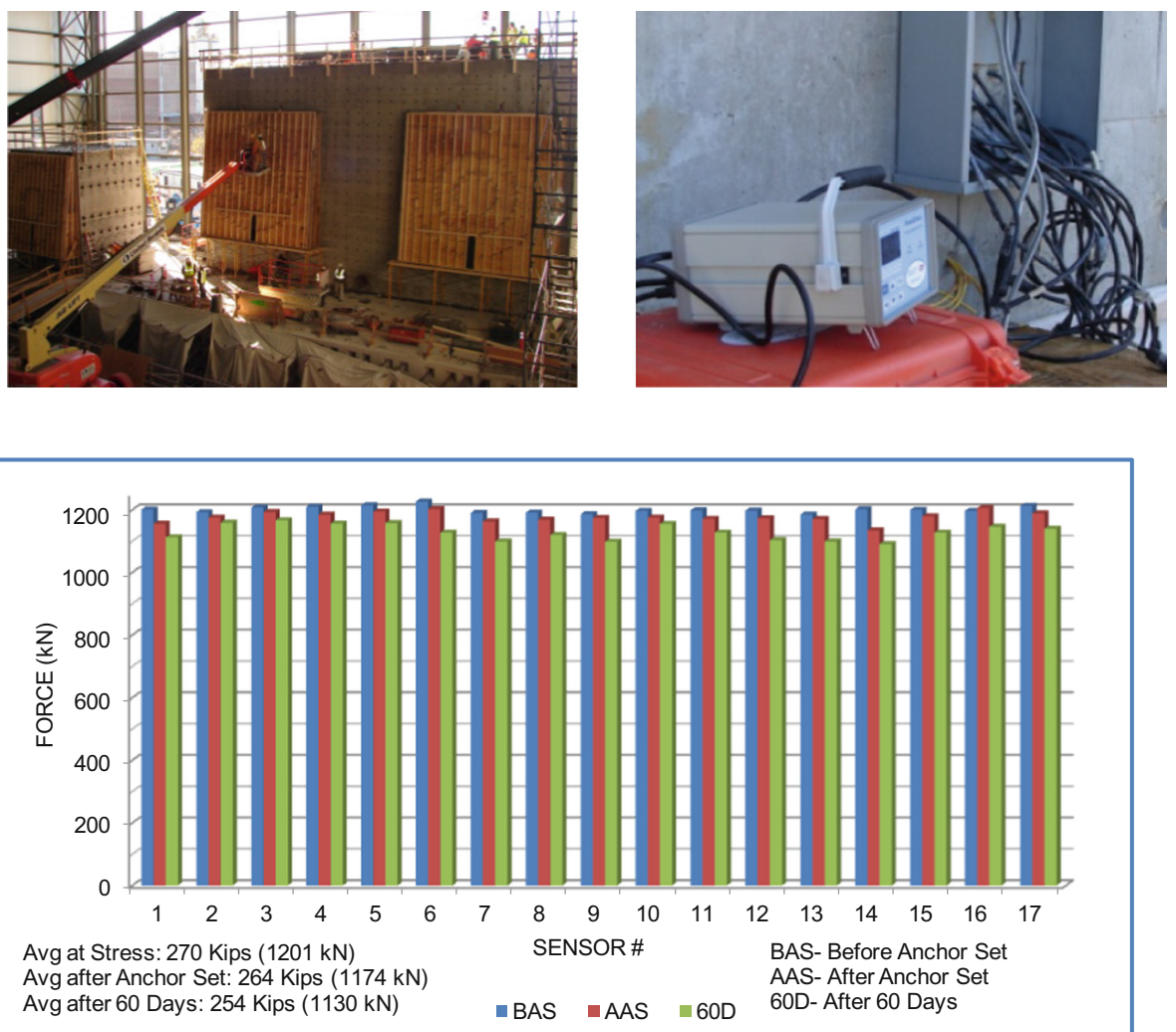

Fig. 8. Sensors for wind technology testing center in Boston, MA, USA

after stressing (Fig. 8). The recorded data proved to be valuable information to validate the design. After dynamic testing of the turbine, the force in the post-tensioned bars will be measured using the sensors to ensure structural safety.

Seventy one sensors were installed on the $66 \mathrm{~mm}$ Gr $1035 \mathrm{MPa}$ Threadbar to monitor the forces in the tension ties installed for the excavation of central portion in Ottawa Light Rail Transit in Canada. The forces were recorded every hour and remotely transmitted so that the engineer can analyze and compare with his analytical model for the safety of the worker to continue. Figure 9 shows the tunnel and sensor installation. The data received provided valuable information to the engineer and the owner. Additional load was applied to the ties based on the sensor readings and the excavation was successfully completed.

Three hundred forty five permanent tieback anchors with 9-0.6 inch diameter strands were used to retrofit the 1700-ft long crib wall of up to 50- $\mathrm{ft}$ tall of the Patton Creek shopping center in Birmingham, AL which showed sign of slow moving. Tie- 

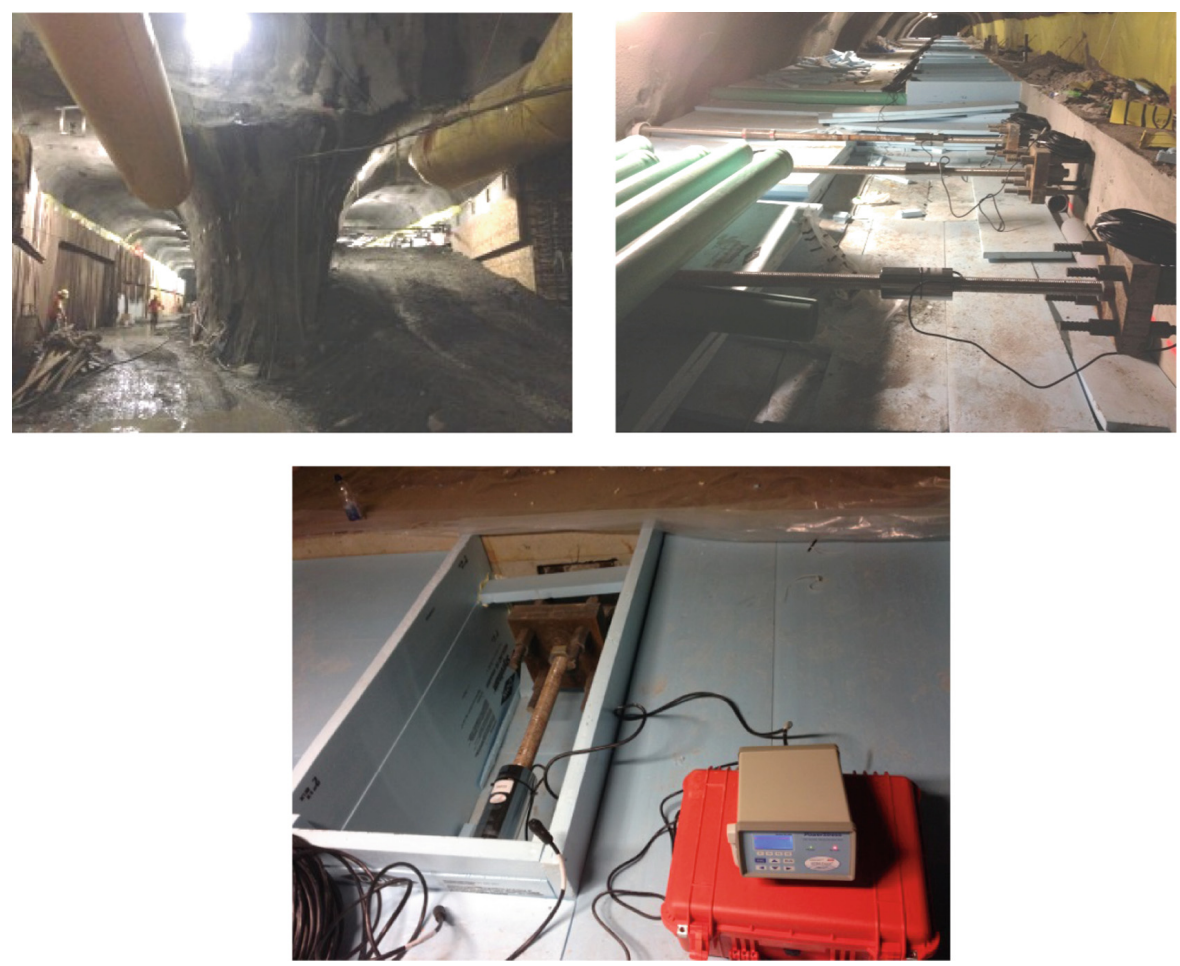

Fig. 9. Sensors for tension ties in Ottawa light rail transit, Ontario, Canada
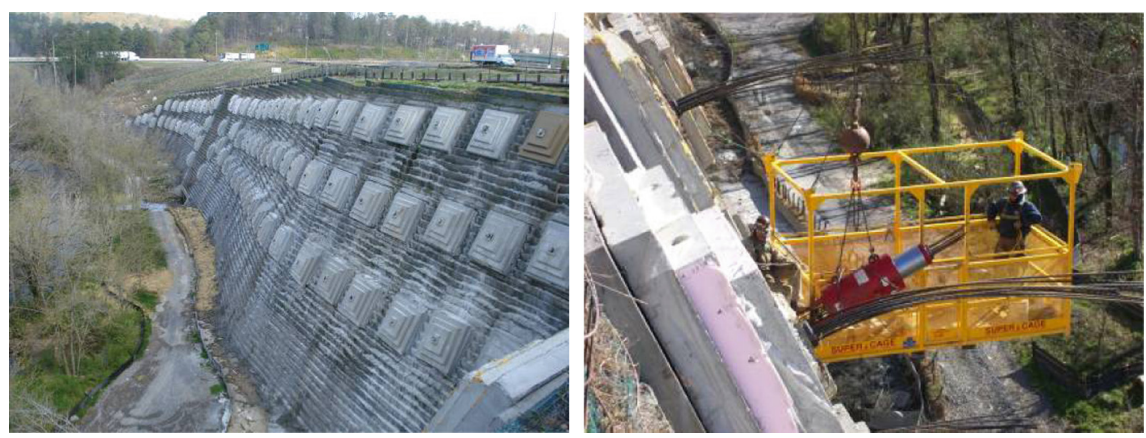

Fig. 10. View of wall with precast units and anchor stressing for Patton Creek complex, Alabama, USA 


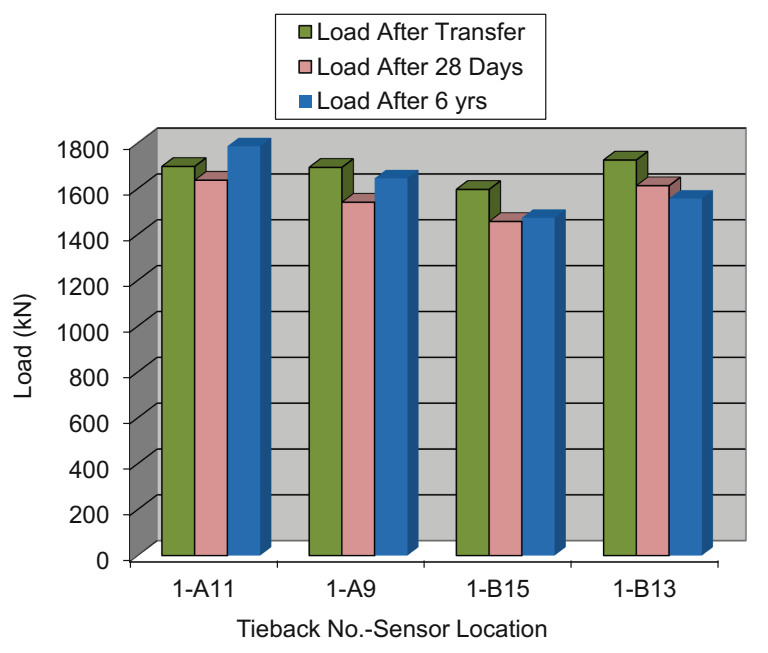

Fig. 11. Anchor force monitoring for slope stability of Patton Creek shopping complex, Alabama, USA

back was fabricated with a double corrosion protection system. Anchors were proof or performance tested to $80 \%$ of strand ultimate strength and locked at a lower load. Partial view of wall with precast units and stressing of anchors are shown in Fig. 10. One sensor was installed in each of 4 anchors and the forces in these anchors were measured after lock-off, after 28 days and after 6 years in service and the results are shown in Fig. 11. The latest data shows the forces in three anchors have increased as compared to 28 days readings. The increase in load in the anchors may be a result of newly opened road adjacent to the anchor wall.

Four-hundred-seventy anchors with 4 thru $815.2 \mathrm{~mm}$ diameter strands were used as tie backs for two permanent retaining walls for a busy road widening in Rt. 405 in Los Angeles, CA, USA as shown in Fig. 12. Forty-eight sensors were installed on tie back anchors to monitor the performance of the retaining wall. Automated readout units were installed to record the force at every $4 \mathrm{~h}$. Sensors are providing very consistent and valuable information to the owner. The sensors are in place for last 3 years and the engineer reported the force readings are very stable suggesting no wall movement.

Roanoke Rapids Dam is located near the town of Roanoke Rapids in North Carolina. It is $930 \mathrm{~m} \mathrm{(3050} \mathrm{ft)} \mathrm{long} \mathrm{and} \mathrm{forms} \mathrm{an} \mathrm{eight-mile-long} \mathrm{reservoir} \mathrm{and} \mathrm{has} \mathrm{been} \mathrm{in}$ operation since 1955. Recent investigation found cracks in the dam. In order to prevent crack from propagation, 30-0.6" (15.2 mm) strand restressable anchorage were installed (See Fig. 13). Each anchor length varies between $30 \mathrm{~m}(98 \mathrm{ft})$ to $40 \mathrm{~m}$ (133 ft) and was made from 30-0.6" epoxy coated strands. Five anchors were equipped with three sensors placed on three different strands. Sensors were used as second load reading during proof test and as future load monitoring. Data is being taken periodically and are very consistent and providing valuable information to the engineer. 
(a)

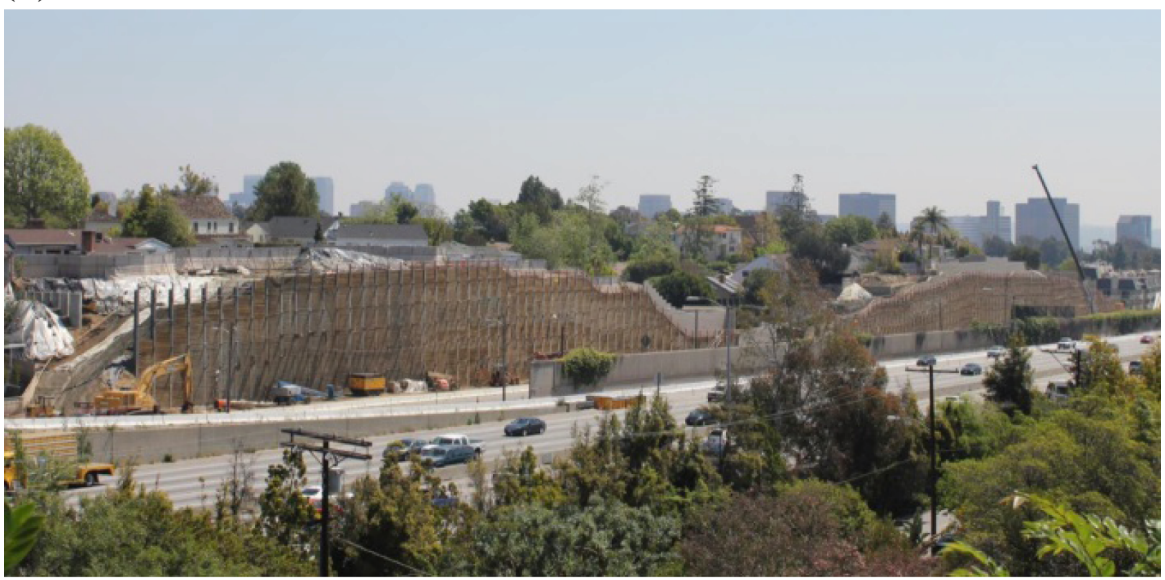

(b)
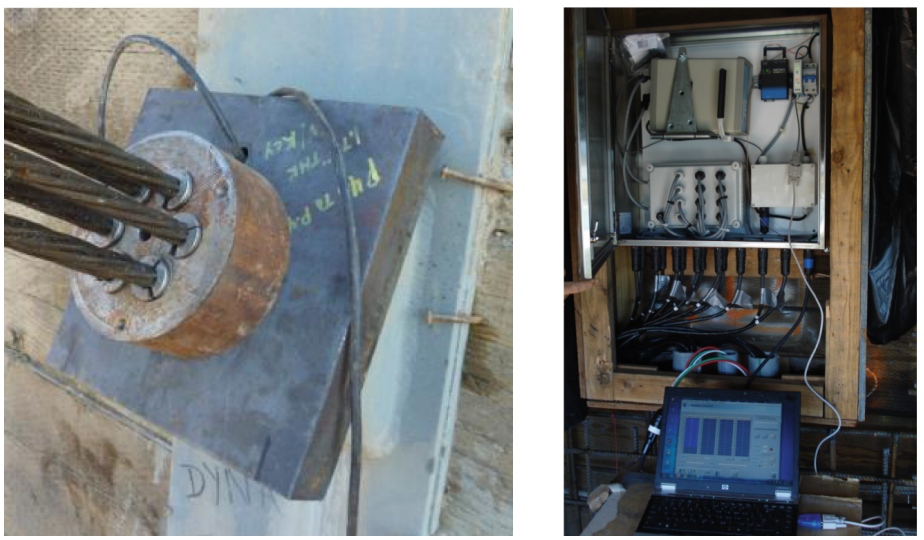

Fig. 12. a. Sensor for retaining walls of Rt 405, Los Angeles, California, USA, b. Sensor for retaining walls of Rt 405, Los Angeles, California, USA

Grancarevo Dam is the largest dam in Balkan region of Bosnia and Herzegovina and it is critical for energy supply in the region. This dam is $120 \mathrm{~m}$ in height and $500 \mathrm{~m}$ long. Strand anchors were installed to stabilize the soil. DSI supplied twenty three $12-062 "(15.7 \mathrm{~mm})$ strand anchors. Four anchors were instrumented with 2 sensors in each of the anchor (See Fig. 14) and the force has been monitored remotely in daily basis for over 18 months. Sensor readings are very accurate and consistent. 

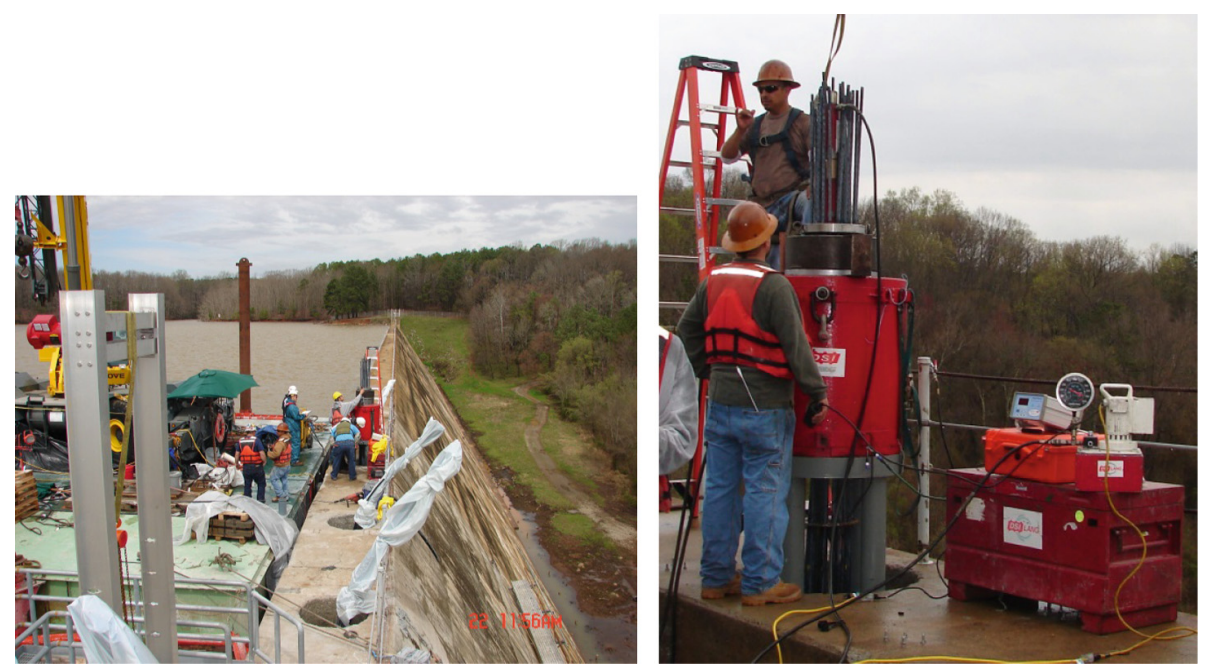

Fig. 13. Sensors for Roanoke Rapids Lake Dam, North Carolina, USA
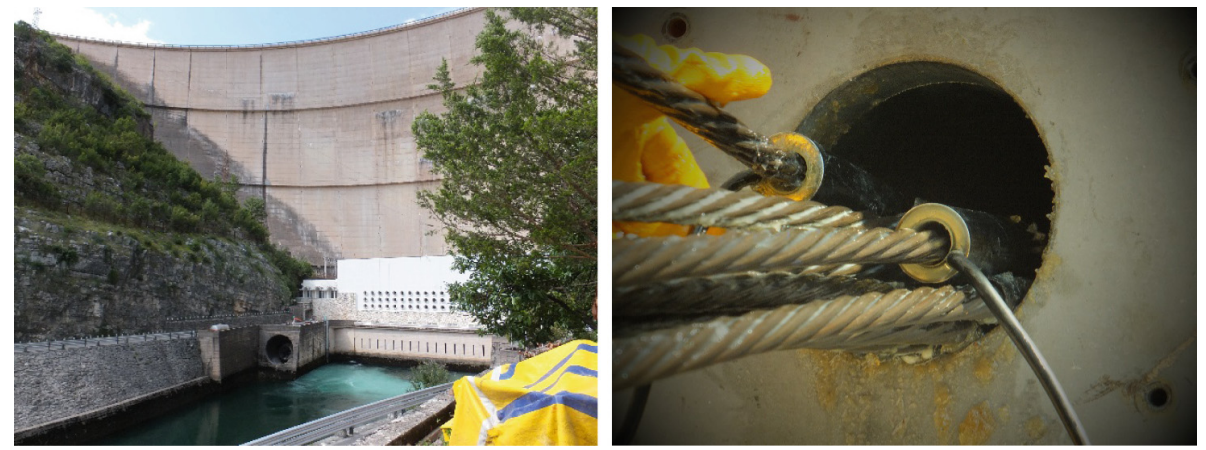

Fig. 14. Sensors in Grancarevo dam, Bosnia and Herzegovina

\section{Conclusions}

Intense research and testing enabled development of elasto-magnetic sensor and its measuring unit. Sensors provide accurate and reliable readings. They have been used in over seventy projects and proven to be the preferred technique to monitor forces in steel elements in terms of accuracy, its performance, ease in installation, durability, and cost effectiveness. The sensors can be used for bare, epoxy-coated, galvanized and greased-sheathed steel in bonded, un-bonded, grouted or un-grouted length of the anchor/stay.

In addition to the long-term monitoring benefit of using the sensor, it may also be used to check the load during stressing to address the safety of the structure. It will eliminate the use of large equipment during lift-off operation. The owner can regularly 
monitor forces in pre-stressing steel manually, continuously and even from a remote access. Forces in the ground anchors obtained from sensors can be used to adjust anchor forces if re-stressable anchors are used.

The accuracy of the force measurement is equal or better than load cells. The sensor is robust, requires no maintenance, has no moving parts and is not subject to any load. It is expected to have a similar service life to that of the surrounding structure.

Acknowledgments. The authors wish to acknowledge the support of Dr. Yang Zhao and Dr. Ming Wang during development and troubleshooting of sensors. Special thanks to Mr. Kerry Allen and Mr. Hans Wlodkowski for their continuous support. The authors would like to thank all members of the GeoMeast 2017 Technical Committee for their support and contribution.

\section{References}

Islam, S., Purinton, K.: Long-term force monitoring of prestressed anchors used on dam rehabilitation projects. In: Dam Safety 2015 Conference, New Orleans, LA, USA (2015)

Islam, S.: Force monitoring of post-tensioned steel elements in bridge and building structures. In: Proceedings the Fourth International Fib Congress, Mumbai, India, pp. 733-737 (2014)

Islam, S.: Long term force monitoring of post-tensioning tendons and cable stays in concrete segmental bridges. In: ASBI International Symposium on Future Technology for Concrete Segmental Bridges, San Francisco, California, USA (2008)

Fabo, P., Chandoga, M., Jarosevic, A.: The smart tendons a new approach to prestressing. In: Fib Symposium, Avignon, France (2004)

Wang, M.L., Koontz, S., Jarosevic, A.: Monitoring of cable forces using magneto-elastic sensors. In: 2nd U.S.-China Symposium Workshop on Recent Developments and Future Trends of Computational Mechanics in Structural Engineering, Dalian, PRC, pp. 337-349 (1998) 